\title{
Construction of Buying Intention Model on Counterfeit Luxury Goods Based on Motivation of Consumption
}

\author{
Yanping $\mathrm{Zhou}^{1} \&$ Cheng $\mathrm{Lu}^{1}$ \\ ${ }^{1}$ Shanghai University of Engineering Science Fashion Institute, Shanghai, China \\ Correspondence: Cheng Lu, Shanghai University of Engineering Science Fashion Institute, Shanghai, China. Tel: \\ 86-139-1746-5127.E-mail: jilabo@126.com
}

Received: September 9, 2014 Accepted: September 24, 2014 Online Published: January 10, 2015

doi:10.5430/sass.v2n1p1 URL: http://dx.doi.org/10.5430/sass.v2n1p1

\section{Fund programs:}

Shanghai municipal education commission innovation project "Coordination mechanism research on retail consuming across the channel "(A2-B-8901-13-0114)

Shanghai University of Engineering Science innovation project "Clothing enterprises binary distribution channel cooperative marketing strategy" (E1-0903-14-01166)

\begin{abstract}
The purpose of this paper is to find the real consumption motivation of counterfeit luxury goods, and to clarify the relationship between buying Intention of counterfeit Luxury goods and consumption motivation of counterfeit luxury goods. The paper opts for an exploratory study using depth interviews and questionnaire, which outline the motivation: price, self-realization, to taste a fresh delicacy, low risk, to show off, to maintain the emotion, to revenge enterprise, deception and conformity. Then implying the factor analysis and regression analysis, we got the real motivation of consumption counterfeit goods and built new modified model between buying intention and motives of counterfeit goods. There are two kinds of motivations including social and personal, and social motivation is on the subject status; counterfeit luxury goods consumption intentions and purchase motives are positive correlation, and social motivation is on the subject status; the influence of gender difference between the buying motivation and intention are not significant. Limited by the scope of the research object, the samples' coverage is limited, so the conclusion's using range needs further improvement. Secondly, this article is to regard luxury as a whole to study, not according to the categorical difference, which will affect the final purchase intentions. This study clarifies the relationship between buying intention of counterfeit luxury goods and consumption motivation of mounterfeit luxury goods, and build new modified buying intention model between them.
\end{abstract}

Keywords: counterfeit luxury, consumer motivation, buying intention model

\section{Introduction}

According to China Luxury Association's report, in 2012 China totally consumed 1, 8365 trillion about luxury goods, and annual growth rate increased by $20 \%$ during the past ten years. Bain \& company's the 2012 China luxury market research report shows that China has become the biggest luxury consumer and almost has purchased a quarter of luxury goods all over the world. What's more, China has been the second luxury market better than Japan. There is no doubt that China has become the biggest customer in the luxury market. It is impossible for China to not have luxury, and it is defective market without luxury (Zhang 2014). At the same time, the counterfeit luxury goods markets are gradually expanding (Zhu 2006). According to the international trade commission estimates, global sales of counterfeit goods in 1982 was $\$ 5.5$ billion, while which has more than $\$ 500$ billion by 2009 , which is worse in China. With the development of economy and improvement of living standards, people are willing to pursue more sophisticated way of life, and internal features in luxuries such as outstanding quality and a status symbol can meet the needs of consumers, which greatly promote the development of the luxury goods industry, as well as counterfeit market. However, during the research, we got that mass counterfeit luxury goods consuming behavior are voluntary. In the past a lot of research suggests that low price is the main factor to buy counterfeit luxury goods. They also 
discussed it from Legal cognition, moral and ethical aspects. It is less to know about the reason why people buy counterfeit luxury goods from the consumers themselves (Eisend \& Pakize 2006). Veblen (1994) pointed that the main reason is conspicuous consumers. Solomon (1983) also thought that symbol is the main reason for consumers to purchase and use them. At the same time, Chinese scholars also pointed out that face, to show off and status are important factors during consumer's luxury consumption (Yuan, Gao, \& Zheng, 2009). Apparently we can find that the symbolic meaning of luxury goods for consumers is much more significant than the practical. This article from the perspective of consumers, and from two aspects including individual and social, try to understand the real consumption of consumer behavior motivation, in addition, want to provide certain help as for reducing or even eliminating counterfeit luxury consumption.

\section{Literature Review}

\subsection{Related Counterfeit Goods Theory}

The American association of international trade defines counterfeit behavior as that some people use registered trademarks of others for the same or similar to the original registered trademark on the goods without authorization. Of course, in China, the state intellectual property office give the definition of it that without the permission of the owner of the registered trademark and patent, using or selling the goods trademark with the patent behavior. There are many definitions about it in the academic world. Bamossy and Scamraon (1985) are those who are firstly defined the counterfeit behavior: the fraudulent activity with putting fake trademark on the goods. It was gradually wide-ranging, including packaging, trademarks and logos (Kay1990), Grossma and Shapiro (1988) thought that it can be divided into two categories, deceptive and not deceptive according consumers' knowledge. The counterfeit luxury goods consumption behavior is largely voluntary consumer (Perez \& Quintanilla, 2010). Therefore, this paper involved in counterfeit luxury goods consumption was conducted on the basis of voluntary without fraudulence.

\subsection{Related Luxury Goods Theory}

Luxury is derived from Latin "luxus", which means something more, later extended to common sense-excessive. Until now has not yet been a definition for luxury goods. Though in different times and cultural background, the specific content of luxury goods are different. Generally, luxury goods has these feature such as high prices, high quality, exclusive, and high psychological value.

\subsection{Related Luxury Consumption Motives Theory}

Due to the particularity of luxury, Veblen (1994) firstly put forward an idea that buying luxury goods is conspicuous consumption, hoping through products to show their social status. Mason (1993) found that American and European luxury consumption motivation is affected by cultural concept, and also reflects that social status played important role in the luxury goods buying motives. Vigneron and Johnson (1999) firstly proposed consumer social motive and personal motivation, and they worked together to promote the consumer decision-making. Scholar CAI (2005) put forward a new dimension for luxury personal guide: ego orientation, mainly including please, gifts, internally consistent and quality assurance. ZHU Xiao-hui (2006) from the perspective of culture, put forward the luxury consumption motives of Chinese consumers, including social luxury consumption motives: to show off, conformity, symbol of social status and personal luxury consumption motives: fine quality, pleasure and gift. Luxury consumption has gone far beyond the significance of the general goods (Shi, 2010), and motivation mainly have largely focused on three bodies:, society, ego and product itself(Tan, 2002).

\subsection{Related Counterfeit Luxury Consumption Motives Theory}

At first, everybody's research focused mainly on price, in their opinion, low price is one of the reasons that attract consumers to buy counterfeit (Tom 1998), consumers can buy counterfeit goods because of the price advantage and could bear the shortage (Bloch \& Campbell, 1993). Wee, Tan \& Cheok (1995) thought in addition to the price factor, symbolism were also important factors for consumers to purchase counterfeits. Chakraborty (1997) pointed out that the consumers purchasing counterfeits had three motives: competition, wealth and status symbol. Phau and Teah (2009) found that, based on the commodity and the symbol of reputation, customers will know the fake and buy fake. Gentry James, Sanjay and Shultz (2006) argued that counterfeit luxury goods can make consumers who intended to buy authentic try this version of brand "cheap", then to buy authentic luxury. Tu Rong-ting (2009), from a perspective of more practical and the consumers' perceptual experience to do some research. Lu Xiao (2009) degarded France, Japan, the Chinese consumers as the object, then the consumer motivation was divided into eight categories. 
We can find that there are many studies on consumption motives, but for each particular factors' the influence degree of motivation, and the study about these influence degree as for the final decisions on consumers to purchase counterfeits are not very rich. So we take university students as the research object, because they are the most precondition to buy counterfeit luxury goods: the pursuit of high status and high quality life, low-income, the high social sensitivity, etc. And from the perspective of personal motivation and social motivation, counterfeit luxury consumption motivation model was constructed finally.

\section{Research Approach}

\subsection{Research Idea}

Based on the domestic college students as the research object, to explore for counterfeit luxury goods consumption motives by empirical research, first of all, we should understand why consumers buy counterfeit luxury goods through the depth interview. Then we will explore whether there are other motives in addition to the common "cost-effective" and "showing off" motives or not. And after qualitative research we use questionnaire survey and statistical analysis of quantitative methods to explore the motivation factors for further verification and build counterfeit luxury consumption motivation model.

\subsection{Qualitative Research}

Through in-depth interviews and combined with relevant theoretical study, the article extracts and analyses the counterfeit luxury consumption motives. Preliminarily analyzes 9 kinds of counterfeit luxury consumption motives: price, self-realization, to taste a fresh delicacy, low risk, to show off, to maintain the emotion, to revenge enterprise, deception and conformity. Among them, the price, self-realization, to taste a fresh delicacy and low risk these four motivation are mainly influenced by individual consumers factors and belong to personal consumption motives; And to show off, to maintain the emotion, to revenge enterprise, deception and conformity these five motivations are influenced by interpersonal factors, so they belong to the social consumption motives.

\subsection{The Construction of the Original Model}

This article regards $I$ as explained variable, $M_{1} 、 M_{2} 、 M_{3} 、 M_{4} 、 M_{5} 、 M_{6} 、 M_{7} 、 M_{8} 、 M_{9}$ as the explaining variable, then builds a regression model which is introduced as follows:

$$
\mathrm{I}=\beta_{0} \mathrm{M}_{1+} \beta_{1} \mathrm{M}_{2}+\beta_{2} \mathrm{M}_{3}+\beta_{3} \mathrm{M}_{4}+\beta_{4} \mathrm{M}_{5}+\beta_{5} \mathrm{M}_{6}+\beta_{6} \mathrm{M}_{7}+\beta_{7} \mathrm{M}_{8}+\beta_{8} \mathrm{M}_{9}+\varepsilon
$$

Among them, I means consumers' intention of purchasing counterfeit luxury, $M_{1} 、 M_{2} 、 M_{3} 、 M_{4} 、 M_{5} 、 M_{6} 、 M_{7}$, $M_{8} 、 M_{9}$ means that price, self-realization, to taste a fresh delicacy, low risk, to show off, to maintain the emotion, to revenge enterprise, deception and conformity, $\beta_{0}, \beta_{1}, \beta_{2}, \beta_{3}, \beta_{4}, \beta_{5}, \beta_{6}, \beta_{7}, \beta_{8}$ are coefficient before explaining variable and $\varepsilon$ as the error term.

\section{Method}

\subsection{Questionnaire Design}

Questionnaire is divided into four parts: part 1 is to measure college students whether have counterfeit consumer experience or not, part 2 measure counterfeit luxury consumption motivation, part 3 measure counterfeit luxury goods purchase intention, the last part is individual's basic information. The first part belongs to deleting selected part, which eliminating invalid questionnaire.

\subsection{Participants}

Regarding college students as research object, the subjects randomly selected 200 people, according to the collected questionnaire validation of the effectiveness of the questionnaire and result of the first part, we eliminate invalid questionnaire, ultimately get 129 the effective questionnaires and effective rate was $64.5 \%$, the amount of males are 68 people, accounting for $52.7 \%$, girls are 61 people, accounting for $47.3 \%$.

\subsection{Measurement of Counterfeit Luxury Goods Motivation and Intention}

Questionnaire option is mainly based on the previous depth interview, at the same time, combining ZHU Xiao-hui (2009). Because of lack of maturity scale for counterfeit luxury goods, meanwhile there are some familiarization, so also reference to BLI scale of Vigneron and Johnson (2004), Wee et al (1995) and TuRongTing motivation scale (2009) and others. The corresponding item of price incentives is 1, 2, 3; self-realization is 4, 5; to taste a fresh delicacy is 6,7 ; low risk is 8 ; to show off is $9,10,11,12$; to maintain the emotion is $13,14,15$; to revenge enterprise 
is $16,17,18$; deception is 19,20 ; conformity is 21,22 . This table uses the five point Likert scale method, according to "strongly disagree", "disagree", "not sure", "agree" to "strongly agree", respectively, to give 1, 2, 3, 4, 5 points. the higher the score, the more match the consumers' motivation. As for measuring consumers purchase intention,we still use the five point Likert scale method, according to the "very reluctant to", "not willing to", "uncertain" and "willing to" to "very willing to", which were given 1, 2, 3, 4, 5 points. The higher the score says the more purchase intention.

The internal consistency coefficient of table is that $\alpha=0.908, \mathrm{KMO}=0.811$, it has good reliability and validity for further analysis.

\subsection{Variable Correlation Test}

Table 1. Regression analysis of motivation factor and purchase intention

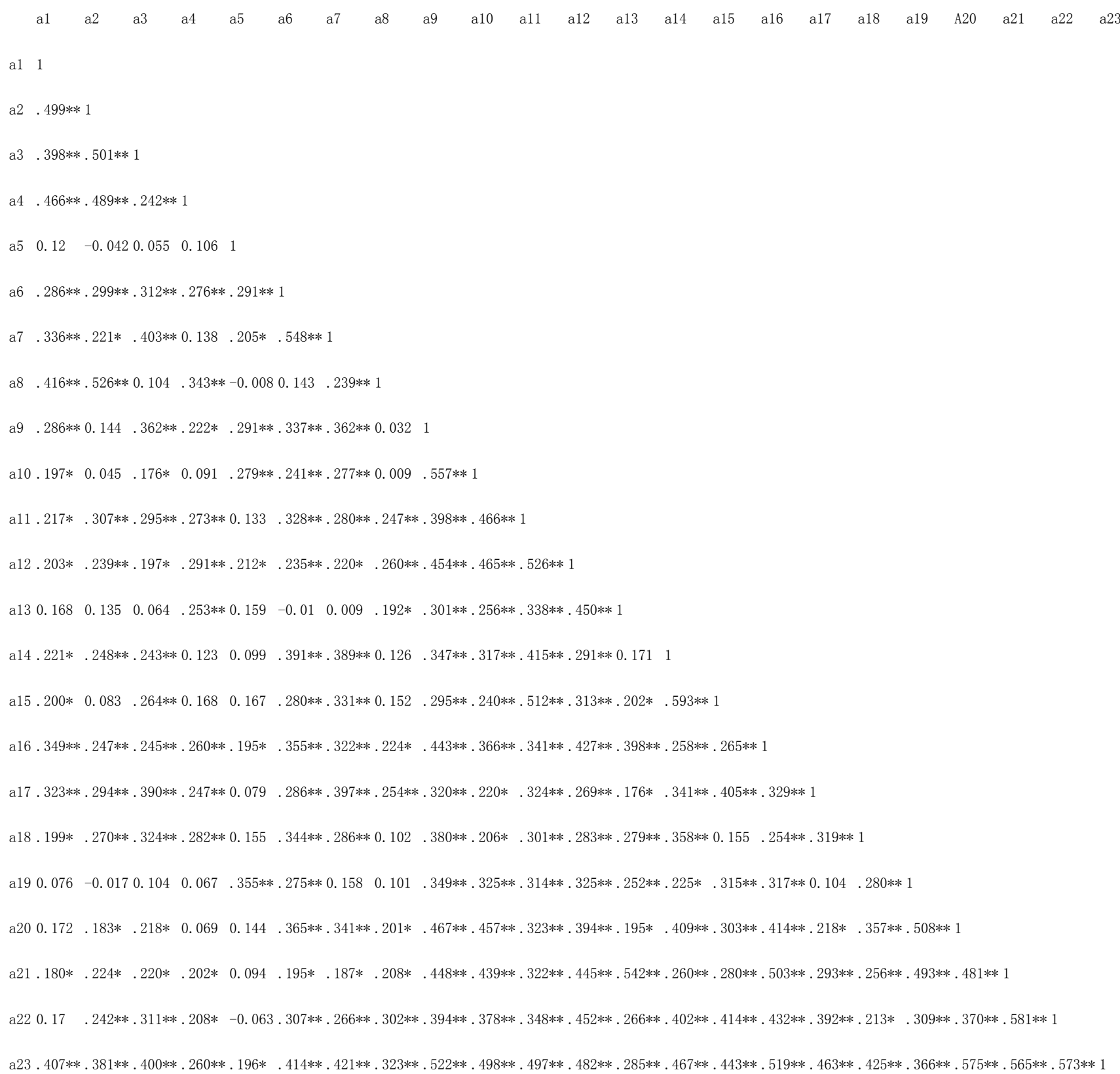

There is a certain correlation between consumers purchase intention (a23) and its influence motivation (a1 - a22) according to table 1, regression analysis is avaliable. And correlation between various motivation is bigger, so this 
paper uses the factor analysis method to extract common motivation factor which affects purchasing intention, in order to eliminate the multidisciplinary problem between the variables.

\subsection{Factor Analysis}

Table 2. Total variance explained table on counterfeit luxury consumption motives

\begin{tabular}{|c|c|c|c|c|c|c|c|c|c|}
\hline \multirow[t]{2}{*}{ Factor } & \multicolumn{3}{|c|}{ Initial eigenvalues } & \multicolumn{3}{|c|}{$\begin{array}{l}\text { Load the extraction of sum of } \\
\text { squares }\end{array}$} & \multicolumn{3}{|c|}{ Load the rotation sum of squares } \\
\hline & total & $\begin{array}{c}\text { explained } \\
\text { variance \% }\end{array}$ & $\begin{array}{l}\text { cumulative } \\
\text { explained } \\
\text { variance } \%\end{array}$ & total & $\begin{array}{c}\text { explained } \\
\text { variance } \%\end{array}$ & $\begin{array}{l}\text { cumulative } \\
\text { explained } \\
\text { variance } \%\end{array}$ & total & $\begin{array}{c}\text { explained } \\
\text { variance } \%\end{array}$ & $\begin{array}{l}\text { cumulative } \\
\text { explained } \\
\text { variance } \%\end{array}$ \\
\hline 1 & 6.997 & 31.804 & 31.804 & 6.997 & 31.804 & 31.804 & 3.771 & 17.139 & 17.139 \\
\hline 2 & 2.193 & 9.966 & 41.771 & 2.193 & 9.966 & 41.771 & 2.784 & 12.656 & 29.794 \\
\hline 3 & 1.644 & 7.471 & 49.242 & 1.644 & 7.471 & 49.242 & 2.622 & 11.919 & 41.714 \\
\hline 4 & 1.305 & 5.933 & 55.175 & 1.305 & 5.933 & 55.175 & 2.131 & 9.686 & 51.4 \\
\hline 5 & 1.047 & 4.759 & 59.934 & 1.047 & 4.759 & 59.934 & 1.446 & 6.571 & 57.971 \\
\hline 6 & 1.004 & 4.565 & 64.499 & 1.004 & 4.565 & 64.499 & 1.436 & 6.527 & 64.499 \\
\hline
\end{tabular}

Through the principal component analysis, the preliminary extraction in the six factors of eigenvalues greater than 1. Data can be seen from table 2: the eigenvalues of the first factor is 6.997 , explained $31.804 \%$ of the total variance of 22 original variables, the cumulative variance contribution rate is $31.804 \%$; The second factor of the characteristic value of 2.193 , explained $9.966 \%$ of the total variance of 22 original variables, the cumulative variance contribution rate of $41.771 \%$; Until the sixth factor characteristic value is 1.004 , explained $4.565 \%$, the cumulative contribution rate was $64.499 \%$. As shown in table (only lists the factors of eigenvalues greater than 1), the six factors explain $64.499 \%$ variance, which are close to $70 \%$, explained the most basic information. After factor rotation, the total cumulative variance contribution rate is constant, have no effect on the original variable joint degrees, but to reallocate the various factors explain the variance of original variables, which makes the factor more easier to understand.

Table 3. Counterfeit luxury consumption motivate factor loading

\begin{tabular}{ccccccc}
\hline Item & \multicolumn{5}{c}{ Factor } \\
\hline & 1 & 2 & 3 & 4 & 5 & 6 \\
a21 & 0.808 & 0.143 & 0.117 & 0.145 & -0.117 & -0.172 \\
a20 & 0.722 & 0.037 & 0.165 & 0.132 & 0.061 & 0.315 \\
a19 & 0.682 & -0.035 & 0.147 & -0.093 & 0.355 & 0.128 \\
a22 & 0.602 & 0.166 & 0.395 & 0.14 & -0.355 & 0.033 \\
a16 & 0.599 & 0.288 & 0.108 & 0.237 & 0.09 & -0.008 \\
a10 & 0.54 & -0.112 & 0.239 & 0.366 & 0.22 & -0.092 \\
a12 & 0.515 & 0.226 & 0.344 & 0.17 & 0.165 & -0.311 \\
\hline
\end{tabular}




\begin{tabular}{ccccccc}
\hline a2 & 0.063 & 0.784 & 0.071 & 0.254 & -0.168 & 0.078 \\
a8 & 0.233 & 0.768 & 0.151 & -0.312 & -0.103 & 0.096 \\
a4 & 0.021 & 0.702 & 0.101 & 0.21 & 0.184 & -0.215 \\
a1 & 0.072 & 0.688 & 0.078 & 0.287 & 0.119 & 0.1 \\
a15 & 0.165 & 0.05 & 0.869 & 0.017 & 0.073 & 0.055 \\
a14 & 0.208 & 0.052 & 0.723 & 0.192 & 0.001 & 0.211 \\
a11 & 0.268 & 0.212 & 0.641 & 0.201 & 0.16 & -0.194 \\
a17 & 0.126 & 0.278 & 0.459 & 0.403 & -0.141 & 0.073 \\
a3 & 0.063 & 0.306 & 0.162 & 0.69 & -0.154 & 0.189 \\
a9 & 0.501 & 0.008 & 0.186 & 0.589 & 0.218 & -0.031 \\
a18 & 0.242 & 0.178 & 0.129 & 0.529 & 0.161 & 0.029 \\
a5 & 0.142 & 0.026 & 0.068 & 0.08 & 0.856 & 0.056 \\
a13 & 0.456 & 0.216 & 0.154 & 0.096 & 0.122 & -0.618 \\
a7 & 0.184 & 0.218 & 0.321 & 0.347 & 0.136 & 0.554 \\
a6 & 0.234 & 0.262 & 0.255 & 0.278 & 0.302 & 0.541
\end{tabular}

This study chooses varimax method as factor rotation method. And order according to the sorting coefficient from big to small, then get counterfeit luxury consumption motivate factor loading table 3 .

Table 4. Comparison table about Motivation factor composition before and after the factor analysis

\begin{tabular}{|c|c|c|c|c|}
\hline New factor & Name & Item & Original factor & Item \\
\hline F1 & vanity & $\begin{array}{l}\text { a10、a12、a16、 } \\
\text { a19、a20、a21 }\end{array}$ & $\begin{array}{l}\text { to show off } \\
\text { conformity } \\
\text { deception }\end{array}$ & $\begin{array}{c}\text { a9、a10、a11、a12; a19、 } \\
\text { a20; a21、a22 }\end{array}$ \\
\hline $\mathrm{F} 2$ & rationality & $\mathrm{a} 1, \mathrm{a} 2 、 \mathrm{a} 4, \mathrm{a} 8$ & price & $a 1, a 2 、 a 3$ \\
\hline F3 & $\begin{array}{l}\text { maintain the } \\
\text { emotion }\end{array}$ & a11a14a15a17 & $\begin{array}{l}\text { to maintain the } \\
\text { emotion }\end{array}$ & a13、a14, a15 \\
\hline $\mathrm{F} 4$ & $\begin{array}{l}\text { to revenge } \\
\text { enterprise }\end{array}$ & a3、a9、a19 & $\begin{array}{l}\text { to revenge } \\
\text { enterprise }\end{array}$ & a16,a17, a18 \\
\hline F5 & $\begin{array}{c}\text { self-realizatio } \\
n\end{array}$ & a5 & self-realization & a4, a5 \\
\hline \multirow[t]{2}{*}{ F6 } & $\begin{array}{l}\text { to taste a } \\
\text { fresh delicacy }\end{array}$ & a6、a7、a13 & $\begin{array}{l}\text { to taste a fresh } \\
\text { delicacy }\end{array}$ & a6、a7 \\
\hline & & & low risk & $\mathrm{a} 8$ \\
\hline
\end{tabular}

After factor analysis, we get the 6 motivation factor. Comparing the composition of the six factors with factor analysis hypothesis before, Measurement results are compared as shown in table 4. 
Six factors are got which we learned From comparison table 4, F1 reflects the original "show, deception, conformity" three factors; Factor F2 and original motive is effective; Factor F3 basically is consistent with original maintaining emotional motivation ; Factor F4 contains motivation ofrevenging enterprises which does not appear before, so it is regarded as to revenge enterprises factor; F5 is basically consistent with the original motivation; F6 also is basically identical with original to taste a fresh delicacy motives. And low risk motive is not thorough, so should give out. At the same time, considering the change of specific situation, it is needed to rename the motivation factors, which can be seen in table 4 .

After factor analysis, explaining the variance and Cronbach's alpha situation of each factor are shown in table 5 .

Table 5. the value of explain the variance of each and Cronbach 's $\alpha$ for each factor After factor analysis

\begin{tabular}{cccc}
\hline New factor & Name & $\begin{array}{c}\text { explained } \\
\text { variance } \%\end{array}$ & Cronbach's $\alpha$ \\
\hline F1 & vanity & 17.139 & 0.837 \\
F2 & $\begin{array}{c}\text { rationality } \\
\text { maintain the } \\
\text { emotion } \\
\text { F3 }\end{array}$ & 12.656 & 0.77 \\
to revenge \\
F4 & 9.686 & 0.753 \\
F5 & $\begin{array}{c}\text { self-realizatio } \\
\text { n }\end{array}$ & 6.571 & 0.621 \\
F6 & $\begin{array}{c}\text { taste a fresh } \\
\text { delicacy }\end{array}$ & 6.527 & 0.658 \\
\hline
\end{tabular}

It is can be found from table 5 that except the to revenge enterprise motivation, the rest of the factors' Cronbach's alpha values are above 0.65, which are in line with the Devellis (1991) standard, meaning that it has good reliability. And in terms of revenging enterprise motivation factor, although Cronbachisa values have not reached 0.65 standard, but still meet Cuieford (1965) proposed by 0.35 standard, and close to 0.6 , it is still an acceptable range.

\subsection{Gender and Counterfeit Luxury Shopping Motives}

There are totally 129 counterfeit luxury consumers samples of this study, male 68 and female 61 . Using independent sample $\mathrm{T}$ test method to compare different gender consumer of counterfeit luxury goods consumption in the motivation factor whether there is a difference. Comparison results are shown in table 6.

Table 6. Independent sample $\mathrm{T}$ test results for counterfeit luxury consumption motives under different gender

\begin{tabular}{ccccccc}
\hline Factor & Gender & $\mathrm{N}$ & mean value & $\begin{array}{c}\text { standard } \\
\text { deviation }\end{array}$ & $\mathrm{t}$ & $\begin{array}{c}\text { Sig.(lbilatera } \\
\text { 1) }\end{array}$ \\
\hline F1 & male & 68 & 0.0953 & 0.8817 & 1.144 & 0.255 \\
& female & 61 & -0.1062 & 1.1151 & & \\
F2 & male & 68 & -0.0649 & 0.9484 & -0.777 & 0.439 \\
& female & 61 & 0.0723 & 1.0577 & & \\
F3 & male & 68 & -0.1394 & 0.9991 & -1.684 & 0.095 \\
& female & 61 & 0.1554 & 0.9859 & & \\
F4 & male & 68 & -0.0049 & 0.9501 & -0.058 & 0.954 \\
& female & 61 & 0.0054 & 1.0607 & & \\
F5 & male & 68 & 0.1657 & 1.1475 & 2.053 & 0.042 \\
& female & 61 & -0.1848 & 0.7727 & & \\
\hline
\end{tabular}




\begin{tabular}{ccccccc}
\hline F6 & male & 68 & 0.0258 & 0.9727 & 0.309 & 0.758 \\
& female & 61 & -0.0288 & 1.0370 & & \\
\hline
\end{tabular}

As is seen from table 6 , the $\mathrm{T}$ test of different gender consumer self-realization motivation significant probability is 0.042 , less than 0.05 , shows that men and women consumers' self-realization motivation has a significant difference at 0.05 level. Men buy counterfeit luxury goods self-fulfilling motivation than women. On the other motives, the difference is not significant.

\subsection{Establishment of the New Model}

According to the extraction in the six common factor of the above factor analysis, This article regard I as explained variable, $F_{1} 、 F_{2}, F_{3} 、 F_{4} 、 F_{5} 、 F_{6}$ as the explaining variable, then build a new regression model which is shown as follows:

$$
\mathrm{I}=\beta_{0} \mathrm{~F}_{1+} \beta_{1} \mathrm{~F}_{2}+\beta_{2} \mathrm{~F}_{3}+\beta_{3} \mathrm{~F}_{4}+\beta_{4} \mathrm{~F}_{5}+\beta_{5} \mathrm{~F}+\varepsilon
$$

Among them, I means consumers' intention of purchasing counterfeit luxury, $F_{1} 、 F_{2} 、 F_{3} 、 F_{4} 、 F_{5} 、 F_{6}$ means that vanity, rationality,to maintain the emotion, revenging enterprise, to taste a fresh delicacy and self-realization., $\beta_{0} 、 \beta_{1} 、 \beta_{2} 、 \beta_{3}$, $\beta_{4} 、 \beta_{5}$ are coefficient before explaining variable and $\varepsilon$ as the error term.

4.8 Regression Result Analysis

Table 7. Regression result

\begin{tabular}{ccccc}
\hline & B & standard error & $\mathrm{t}$ & Sig. \\
\hline $\mathrm{F}_{1}$ & 0.528 & 0.053 & 9.916 & 0 \\
$\mathrm{~F}_{2}$ & 0.273 & 0.053 & 5.12 & 0 \\
$\mathrm{~F}_{3}$ & 0.35 & 0.053 & 6.581 & 0 \\
$\mathrm{~F}_{4}$ & 0.307 & 0.053 & 5.771 & 0 \\
$\mathrm{~F}_{5}$ & 0.017 & 0.053 & 0.32 & 0.75 \\
$\mathrm{~F}_{6}$ & 0.11 & 0.053 & 2.066 & 0.041 \\
$\mathrm{~F}_{\text {value }}$ & \multicolumn{3}{c}{34.256} \\
$\mathrm{R}^{2}$ & \multicolumn{3}{c}{0.628} \\
\hline
\end{tabular}

Based on the data of $I 、 F_{1} 、 F_{2} 、 F_{3} 、 F_{4} 、 F_{5} 、 F_{6}$ in this paper, using regression analysis, the specific results are shown in table 7. According to the results in the table, value of $\mathrm{R}^{2}$ is 0.628 , which illustrate the six variables ultimately explain $62.8 \%$ as for counterfeit luxury goods purchase intention of consumers. Since this study is from the perspective of consumer motivation to explore consumer's purchase intention of fake luxury goods, if added other relevant factors, equation of degree of explanation would be further improved. And vanity, rational, to maintain the emotion, to revenge enterprise and to taste a fresh delicacy these five variables passed the test of significance and the corresponding coefficient is the plus sign, which means that these are closely relative to their impact on consumers, and the variable of self-realization dose not pass through the test of significance, consumers' the influence of motivation of self-realization as for counterfeit luxury goods consuming intention is not very significant.

\section{Conclusion}

\subsection{Counterfeit Luxury Consumption Motives of Consumers Include Social Motivation and Personal Motivation, and Social Motive Occuies the Main Body Status}

At the beginning the article assumed counterfeit consumer motivation including social motive: to show off, to maintain the emotion, to revenge enterprise, deception, conformity; personal motivation: price, self-realization, to to taste a fresh delicacy, and low risk. And according to factor analysis, there are really six motivation factor, and among them that vanity, to maintain the emotion, to revenge enterprise belong to social motives, the rationality, to to taste a fresh delicacy and self-realization are personal motives. Previous hypothesis part was established, overall explained variance of the social motivation is $38.744 \%$, accounting for $60.069 \%$ of all factors explain $64.499 \%$ 
variance, finds that social motive is dominant. Vanity, to maintain the emotion and to revenge enterprise have great role in counterfeit luxury goods consumption. Among them, the explained variance of vanity after the rotation was $17.139 \%$, which is the largest proportion.

\subsection{Counterfeit Luxury Goods Purchase Intentions and Purchase Motives Are Positively Related, and the Social} Motive Occupys the Main Body Status

According to the regression analysis and the new model, counterfeit luxury goods purchase intentions and buying motives are positively related, the vanity, rationality, to maintain the emotion, to revenge enterprise and to to taste a fresh delicacy these five variables passed the test of significance, the corresponding coefficients are the plus sign, which means that these are closely relative to their impact on consumers. Combined with previous factor analysis, social motivation has more great impact on the final purchase intention of consumers. Although self-realization didn't pass the test, but with ever increasing consumer pursuit of a refined, sophisticated life, self-realization motivation is likely to be counterfeit luxury consumption motives. So we can not ignore its influence.

\subsection{Gender Differences as to Counterfeit Luxury Goods Purchase Motive and Intention Was not Significant}

According to the $\mathrm{T}$ test, we can significantly find that the gender on consumers' buying motivations and purchase intentions was not significant, only when motivation is self-realization, which has significant difference at 0.05 level. Men's self-realization motivation of buying counterfeit luxury goods is higher than women's, which means Gender differences as to counterfeit luxury goods purchase motive and intention were not significant. Because the research objects are college students, so their age, income and education degree are almost the same, so there is no separate as variables are discussed.

\subsection{Discussion and Prospect}

Increasingly rampant counterfeit luxury goods industry, and is closely related to growing consumer demand. At the social level, through high simulated luxury, consumers try to show off the people about his value and status in society, it is the primary motivation of consumer's consumption of fake goods. Because luxury its own unique features that social value is far higher than that of use value so that having such a luxury for some people is to have a high social recognition. Secondly, this also is the need of emotional connection and the society, as well as the cost is not high prices, so why not? Moreover, with the growth of consumers' self-awareness, they are dissatisfied with the social enterprise profits phenomenon greatly, so they are trying to buy replicas, retaliation to large enterprises, to revenge them against market economic behavior; In terms of individual consumers, firstly, with the cause of the vast majority of consumers to purchase counterfeits are consistent, the main cause of the consumers to purchase counterfeit luxury goods is good and inexpensive, they can lower the price to buy good quality goods, which is the most ordinary people is not exclusive. Second is to to taste a fresh delicacy, by buying a similar knockoffs, understanding the quality of products, which can reduce the risks of the consumer to buy genuine but also reducing the unnecessary spending, it is this advantage to promote the consumer to buy. Of course, more and more sophisticated fake luxury goods would attract more those who try to be in conformity with their own temperament by buying products. It is different from social status and to show off, which just enjoy themselves, the phenomenon reflecting the functions of the luxury such as promoting self-improvement and maintaining the role of self-esteem.

Although there are many counterfeit luxury goods consumer motivation, including social motives and personal motivation, specifically including others, not all will influence final purchase intentions. Study found that social motive influence on consumers' purchase intention of counterfeit luxury is more significant,which means that the current social motivation is still the main reason. People hope to show his value and status in society with the help of a product. At the same time, as for this research, gender in the counterfeit luxury goods consumption behavior of consumers is not so significant, so such a behavior is a common phenomenon, not only the men and women have.

According to the above research conclusion, our government should actively expand public opinion direction, showing that consumer social position is exactly equal, and timely to reward excellent employees. whatsmore, government should actively improve the system of social welfare and improve consumer's social status so that alleviate their panic due to the lack of real status, otherwise they would like to use external things to improve their behavior; For our company, in addition to increasing counterfeit prevention measures, it is necessary to intensify propaganda brand value and enhance the consumers' awareness of enterprise brand's value. It is better to make consumers not only focus on the product itself, but also pay more attention to the added value of products. Enterprises should also be appropriate to lower the price of products, studies have shown that if the price between authenticity and replicas are in about 5 times, consumers are more willing to buy genuine; In the light of consumer itself, they should set up the correct outlook on life, world outlook and values, having efforts to improve its value is 
eternal truth. To buy counterfeit luxury goods will reduce its value, and may do harm to business interests and bring devastating hit as to the formation of the stable social pattern and economic development.

\section{Limitation}

Limited by the scope of the research object, the sample coverage is limited, so the conclusion's using range needs further improvement. Secondly, this article is to regard luxury as a whole to study, not according to the categories' different, which will affect the final purchase intentions, these aspects are in-depth research about counterfeit luxury consumer behavior .

\section{References}

Bamossy, G., \& Scammon, D. L. (1985). Product counterfeiting:consumers and manufacturers beware. Advances in Consumer Research, 89(12), 334-340.

Bloch, P. H., Bush, R. F., \& Campbell, L. (1993). Consumer, accomplices in product counterfeiting: A demand-side investigation. Journal of Consumer Marketing, 10(4), 17-36.

Chakraborty, G., Allred, A., \& Sukhdial, A. S. (1997), Use of negative cues to reduce demand for counterfeit products. Advances in Consumer Research, 24(3), 345-349.

Eisend, M., \& Pakize, S. (2006). Explaining counterfeit purchases; a review and preview. Academy of Marketing Review, November 12.

Grossman, G. M., \& Shapiro, C. (1988). Counterfeit-product Trade. The American Economic Review, 78(1), 59-75.

Gentry, James W., Putrevu, Sanjay, \& Shultz, Clifford J. (2006). The effects of counterfeiting on consumer search. Journal of Consumer Behaviour, 5(3), 245-256.

Kay, H. (1990). Fake's Progress. Management Today, 1, 54-58.

Lu, C. B., Qing, Q. X., \& Lin, Y. Y. (2013). A theoretical model about luxury consumption characteristic and its dimensions. Management Review, 26(5), 123-135.

Li, Y. N. (2013). Research of counterfeit luxury consumption motivation and influencing factors. Unpublished doctoral dissertation, Zhejiang University, Zhejiang

Mason, \& Roger. (1993). Cross-cultural influences on the demand for status goods. European Advances in Consumer Research, 1, 46-51.

Nia, A., \& Zaichkowsky, J. L. (2000). Do Counterfeits Devalue the Ownership of Luxury Brands?. Journal of product \& Brand Management, 9(7), 485-497.

Phau, I., \& Teah, M. (2009). Devil wears (counterfeit) Prada: a study of antecedents and outcomes of attitudes towards counterfeits of luxury brands. Journal of Consumer Marketing, 26(1), 15-27.

Tan, B. (2002). Understanding consumer ethical decision making with respect to purchase of pirated software. Journal of Consumer Marketing, 19(2), 96-111.

Tom, G., Garibaldi, B., \& Zeng, Y. (1998). Consumer demand for counterfeit goods. Psychology \& Marketing, 15(5), 405-421.

Vgneron, F., \& Johnson, L. W. A. (1999). Review and a conceptual framework of prestige-seeking consumer behavior. Academy of Marketing Science Review, 45(3), 237-261.

Veblen, T. (1994). The theory of the leisure. Chicago: The University of Chicago Press.

Shi, A. N. (2010). Research on the factors of consumer's intention to purchase counterfeit luxury good. Unpublished doctoral dissertation, Shanghai Jiao Tong University, Shanghai.

Wee, C. H., Tan, S. J., \& Cheok, K. H. (1995). Non-price determinants of intention to purchase counterfeit goods: an exploratory study. International Marketing Review, 12(6), 19-46.

Yuan, S. F., Gao, Y. \& Zheng, Y. X. (2009). Face consciousness, status consumption tendency and conspicuous consumption behavior-theoretical relationship model and empirical Research. Collected Essays on Finance and Economics, 146(5), 81-86.

Zhang, B. (2014). Luxury goods failed at China. Shanghai Economy, 246(1), 62-64. 
Zhu, X. H. (2006). An empirical research on ruxury consumption cotives of Chinese consumers. Business Economics and Administration, 177(7), 42-48. 